BIOMEDICA

Vol. 1, No. $4-1981$

\title{
TRATAMIENTO DE LAS PARASITOSIS INTESTINALES FRECUENTES EN COLOMBIA
}

\author{
DAVID BOTERO.*
}

En la última década se han obtenido importantes avances en el tratamiento de las parasitosis intestinales $(1,2)$. La droga ideal, efectiva en dosis única contra todos o la mayoría de los parásitos del intestino, de bajo costo y sin toxicidad, todavía no se ha logrado. El enorme número de personas parasitadas, la mayoría de bajos recursos económicos y el uso de tratamientos en masa como medida de salud pública, hacen necesaria la obtención de nuevos medicamentos apropiados para este fin (3). Mencionaremos inicialmente las parasitósis y las drogas recomendadas y nos referiremos posteriormente a las drogas con más detalle.

Amibiasis

Siempre que haya amibiasis intestinal sintomática es necesario utilizar dos drogas: una que actúe contra los parásitos en los tejidos y otra que los destruya en la luz intestinal. No existe en la actualidad una droga única con ambas acciones totalmente efectivas. Los medicamentos de elección contra las amibas tisulares son los nitroimidazoles y los que las atacan en la luz son los derivados dicloroacetamídicos. Una droga alternativa en las formas tisulares es la dehidroemetina. En la amibiasis intestinal asintomática es suficiente el uso de las dicloacetamidas.

\section{Giardiasis}

Son tan efectivos los nitroimidazoles como la furazolidona. Los primeros tienen la ventaja de la eficiencia en dosis única o en tratamiento de pocos días.

\section{Balantidiasis}

Aunque tradicionalmente se han utilizado los antiamibianos se conocen estudios recientes que han demostrado la eficiencia del metronidazol y del nimorazol.

\section{Ascariasis}

Las dos drogas más efectivas son el pamoato de pirantel y el mebendazol. Son alternativas el levamisol y la piperazina.

\section{Tricocefalosis}

El mebendazol es la droga más utilizada. El pamoato de oxantel es similar en su acción.

\section{Uncinariasis}

Tanto el pamoato de pirantel como el mebendazol son recomendados como las drogas de elección. No es justificado en la actualidad usar otras drogas en Colombia.

\section{Estrongiloidiasis}

La única droga efectiva es el tiabendazol.

\section{Oxiuriasis}

El pamoato de pirantel y el mebendazol constituyen el tratamiento de elección. Como alternativa existe la piperazina.

\footnotetext{
* Profesor Titular de Parasitología. Facultad de Medicina, Universidad Nacional de Antioquia. Consultor ad-honorem. Instituto Nacional de Salud
} 


\section{Teniasis}

La única droga comercial recomendable es la niclosamida. El Praziquantel tiene ventajas sobre la anterior, pero no se obtiene aún comercialmente en Colombia.

\section{DESCRIPCION DE LAS DROGAS}

Las drogas para las parasitosis intestinales pueden clasificarse en la actualidad en 3 grupos:

1. Las de elección: nitroimidazoles, dicloroacetamidas, pamoato de pirantel, oxantel, mebendazol, tiabendazol, niclosamida y praziquantel. Estas se describirán en detalle, en relación con su modo de acción, toxicidad, efectos secundarios, contraindicaciones, utilización y dosis en tratamientos individuales y en masa.

2. Alternas: emetina y dehidroemetina, furazolidona, levamisol y piperazina.

3. Drogas aún en el mercado, cuyo uso no está justificado: hidroxiquinoleinas, paromomicina, hidroxinaftoato de befenio, tetracloroetileno y pamoato de pirvinio. Estas drogas no se describirán en esta presentación.

\section{DROGAS CONTRA LOS PROTOZOOS}

A. Amebicidas Orales de Acción Principal Tisular.

\section{Derivados nitroimidazólicos}

Se administran únicamente por vía oral, se absorben activamente en el intestino delgado y por esta razón su actividad principal es en los tejidos. Alguna parte de la droga, no absorbida o sus metabolitos eliminados por la bilis, tienen acción parcial contra los parásitos en la luz intestinal. Estas drogas no son recomendadas para tratamientos en masa o para programas quimioprofilácticos. Los nitroimidazoles más utilizados son:

\section{Metronidazol:}

Fue el primer compuesto del grupo que se usó contra una protozoosis, la tricomoniasis vaginal. Posteriormente se extendió su uso a la amibiasis, giardiasis y balantidiasis. Es un compuesto cristalino, soluble en agua, que después de ingerido pasa a la sangre en concentraciones efectivas en 2 a 3 horas, niveles que se mantienen por 12 horas después de una dosis única. Se excreta principalmente por la orina, la cual puede tomar un color rojizo. También se elimina como un metabolito con acción antiparasitaria por la bilis, saliva, semen, secreciones vaginales y leche. Atraviesa la placenta y puede actuar en el feto, lo cual limita su uso durante el embarazo.

Tiene sabor amargo y produce efectos colaterales en 15 a $30 \%$ de los casos, principalmente en el aparato gastrointestinal: náuseas, vómito, dolor abdominal, diarrea y sabor metálico en la boca. Otros síntomas en el SNC son mareos, dolor o entumecimiento en las extremidades y cefalea (4). La inhibición de enzimas que actúan en el metabolismo del alcohol es la causa del efecto potencializador de éste, con producción de mareo fuerte, congestión cutánea, vómitos, cefalea y ocasionalmente confusión mental e hipotensión. Está contraindicado cuando haya enfermedades del SNC y en discracias sanguíneas y no es recomendable en el primer trimestre del embarazo. Potencialmente se ha considerado carcinogenético, pues a altas dosis por largo tiempo produce tumores en roedores y mutaciones bacterianas in vitro (5). A pesar de lo anterior se considera que a dosis terapéuticas no tiene relación con cáncer humano y su utilización como antiparasitario no ha sido restringida.

La dosis utilizada para amibiasis intestinal sintomática y balantidiasis es de $30 \mathrm{mg} / \mathrm{kg} /$ día, subdividida en varias tomas, durante 8 a 10 días. En giardiasis es suficiente la mitad de la dosis diaria, durante 5 días (6). Recientemente apareció una presentación parenteral que tiene utilidad especial en casos graves de amibiasis. Viene 1 frasco de $100 \mathrm{ml}$, que contienen 500 $\mathrm{mg} / \mathrm{ml}$, para uso intravenoso diluído en solución isotónica, por venoclisis lenta.

\section{Timidazol}

Esta droga se absorve rápidamente en el intestino, alcanza altas concentraciones 
sanguíneas a las 24 horas de administrada y permanece en los tejidos por un tiempo largo. Se elimina como timidazol y no como un metabolito, por la bilis y por la orina. Los efectos colaterales son pocos y cuando se presentan son similares a los descritos para el metronidazol. Como éste, atraviesa la plancenta y presenta reacciones desfavorables cuando durante su uso se consume alcohol.

La dosis más utilizada para amibiasis intestinal en adultos es de $2 \mathrm{gm}$. al día después de una comida, durante dos días. En niños la dosis es de $60 \mathrm{mg} / \mathrm{kg} /$ día en una sola dosis por 2 a 3 días. Su actividad a la dosis mencionada es muy buena contra los trofozoitos tisulares (7). Su acción es poca contra los parásitos que están en la luz intestinal (8). En la giardiasis es efectiva una dosis única de $2 \mathrm{gm}$ para adultos y de 60 mg para niños (9).

\section{Omidazol}

Desde el punto de vista farmacológico es similar a los de dos compuestos mencionados, pero con algunas características propias como son: elevada concentración sanguínea en una a dos horas después de administrado, larga duración en el plasma y en los tejidos y eliminación lenta por orina y heces. Como en los otros imidazoles no se recomienda en el primer trimestre del embarazo. No presenta actividad carcinogenética y no tiene incompatibilidad con el alcohol (10).

La dosis recomendada para amibiasis intestinal sintomática y para giardiasis es de $500 \mathrm{mg}$ dos veces al día, por 5 a 10 días en los adultos y dosis proporcionalmente menores para niños. La efectividad terapéutica y la tolerancia son similares a las del metronidazol (4).

\section{Nimorazol:}

Los estudios experimentales con este compuesto han mostrado altas concentraciones sanguíneas y tisurales después de la administración oral. Las dosis utilizadas para amibiasis intestinal y giardiasis son de $40 \mathrm{mg} / \mathrm{kg} /$ día fraccionados, durante 5 a 10 días. En balantidiasis se ha encontrado que la misma dosificación tiene resultados positivos (11). Las contraindicaciones y efectos secundarios son similares a las de otros nitroimidazoles.

\section{B. Amebicidas Parenterales con Acción Unica Tisular}

\section{Emetina y dehidroemetina}

El clorohidrato de emetina se ha utilizado por más de 50 años; se deriva de la ipecacuana, planta de la cual se extrae el éster de cefalina. La vía oral es mal tolerada y poco efectiva: cuando se inyecta se deposita en los tejidos y se elimina lentamente, por lo cual los efectos tóxicos son acumulativos. Los efectos secundarios son dolor en el punto de inyección, náuseas y diarrea.

Los efectos tóxicos son cardiovasculares y neuromusculares; los primeros consisten en hipotensión, taquicardia, arritmia y ocasionalmente insuficiencia cardiaca. La acción sobre los nervios periféricos se manifiesta por dolores y debilidad muscular. Por lo anterior, se recomienda administrar la droga con el paciente en reposo y no utilizarla en ancianos, durante el embarazo y cuando hay afecciones cardiovasculares o neuromusculares.

La dehidroemetina es el compuesto sintético más reciente, con aplicaciones y efectos similares, pero con menor toxicidad. Las dos drogas se utilizan en dosis de 1 a $1.5 \mathrm{mg} / \mathrm{k} /$ día durante 4 a 6 días (12).

\section{Amebicidas Orales de Acción Unica en la Luz Intestinal}

\section{Derivados dicloroacetamídicos (amidas):}

Estos compuestos son insolubles en agua y se absorben muy poco en el intestino. Actúan contra los trofozoítos de amiba por contacto directo y no tienen actividad contra los quistes, pues estos, debido a su membrana protectora, no son afectados por inguna droga antiamibiana. La actividad antiamibiana de las amidas se ejerce a diluciones tan altas como 1:80.000. La acción tóxica es nula a dosis terapéuticas y no se conocen 
contraindicaciones. El único efecto secundario es la flatulencia, que desaparece al terminar el tratamiento.

Las indicaciones de estas drogas son: a) como tratamiento único en portadores asintomáticos, en quienes no hay invasión amibiana de los tejidos, b) en la quimioprofilaxis de la amibiasis, administrados en dosis de 100 a $200 \mathrm{mg}$, 2 a 3 veces por semana (13-14). c) en la amibiasis intestinal sintomática asociada a los antiamibianos que actúan en los tejidos.

Las principales amidas y sus dosis terapéuticas son:

\section{Teclozán:}

La dosis recomendada en mayores de 8 años es de $100 \mathrm{mg} 3$ veces al día por 5 días o de $500 \mathrm{mg}$ al día por 3 días. En menores se recomienda 25 a $50 \mathrm{mg} 3$ veces al día por 5 días (13).

\section{Etofamida:}

Se recomiendan 3 comprimidos diarios de $200 \mathrm{mg}$ por 5 días o cinco comprimidos diarios por 3 días (14).

\section{Antigiardiasicos}

Nitroimidazoles (ya mencionados). Furazolidona:

Este compuesto derivado de los nitrofuranos es de color amarillento parcialmente soluble en agua y parcialmente absorbible en el intestino. Se elimina por la orina a la que puede dar un tinte café. Además de ser efectivo en giardiasis actúa como bactericida intestinal, tanto contra Gram negativos como positivos. Los efectos secundarios ocurren principalmente en el tracto digestivo, tales como náuseas, vómito, anorexia, dolor abdominal y diarrea. Los efectos tóxicos se presentan raramente y pueden incluir brote cutáneo, hemólisis, agranulocitosis y potencialización de la acción del alcohol.

La dosis para adultos es de $100 \mathrm{mg} .4$ veces al día durante 6 días. Para niños mayores de 5 años la dosis se reduce a la mitad. Para menores de esa edad es de 16 $\mathrm{mg} / \mathrm{kg} /$ día, subdividida en 4 dosis por 3 días. Esto es equivalente a 2 gotas por $\mathrm{kg}$. 4 veces al día, cuando se usa el preparado pediátrico que tiene $15 \mathrm{mg}$ por $\mathrm{ml}$, (15).

\section{DROGAS ANTIHELMINTICAS}

\section{Pamoato de Pirantel}

Químicamente es tetrahidropirimidina, un polvo insoluble en agua y muy poco absorbible en el intestino. No tiene sabor especial y es estable a la luz, humedad y temperatura. Actúa contra los helmintos inhibiendo la transmisión neuromuscular y produciendo parálisis espástica de los parásitos. No presenta toxicidad a dosis terapéuticas y es bien tolerado. Entre 4 y $20 \%$ de los pacientes tratados pueden presentar alguna sintomatología leve, principalmente del tracto gastrointestinal. Con este producto no se observa ninguna actividad teratogénica y no tiene contraindicaciones conocidas. El pirantel es efectivo para ascariasis y oxiuriasis a dosis única de $10 \mathrm{mg} / \mathrm{kg}$. Para necatoriasis esta dosis debe repetirse por 3 días consecutivos.

Para estas 3 parasitosis se ha utilizado en tratamientos en masa, con muy buenos resultados. Este procedimiento que es un importante coadyuvante a las medidas de salud pública para el control de las helmintiasis intestinales, se ha puesto en práctica en varios países, especialmente en grupos de edad escolar. Prevalencias de $80 \%$ de ascariasis se han logrado bajar a alrededor del $1 \%$ con esta única medida. Nuestra experiencia en el control de uncinariasis en una zona cafetera de Colombia fue muy exitosa y demostró además la buena tolerancia y aceptación de la droga (16).

\section{Pamoato de oxantel:}

Este compuesto análogo del pirantel es una metilpirimidina. No es efectivo en ascariasis, pero sí en tricocefalosis. Por esta razón la combinación de las dos drogas presentaría amplio espectro de acción, muy útil en casos de helmintiasis múltiples por ascariasis, oxiuriasis, uncinariasis y tricocefalosis. Con esta combinación se han 
obtenido muy buenos resultados en tratamientos en masa. La dosis de oxantel para tricocefalosis es de 10 a $15 \mathrm{mg} . / \mathrm{kg} /$ día por 2 a 3 días. En tricocefalosis leves la dosis única es efectiva (17).

\section{Mebendazol:}

Esta droga pertenece al grupo de los benzimidazoles. Es un polvo blanco-amarillento, muy poco soluble en agua, sin sabor especial y con absorción mínima en el intestino. Actúa al inhibir la utilización de glucosa, lo que determina la muerte lenta del parásito. Su tolerancia es en general buena y no se conocen efectos tóxicos a dosis terapéuticas, aunque no se recomienda durante los primeros meses del embarazo, debido a los hallazgos experimentales que han comprobado efectos teratogénicos en roedores, consistentes en deformidades esqueléticas en la cola y en las costillas. En algunos niños con intenso parasitismo por Ascaris se ha observado la eliminación de estos parásitos por boca y naríz durante el tratamiento o poco después de terminado, lo cual ha hecho pensar en una actividad migratoria de los parásitos causada por el mebendazol (18). Este medicamento es efectivo para tricocéfalos, áscaris, uncinarias y oxiuros a la dosis de $100 \mathrm{mg}$. 2 veces al día por 3 días, para todas las edades (10). Para ascariasis y oxiuriasis las dosis únicas son efectivas. Para teniasis solium y saginata se ha comunicado su efectividad en dosis de $300 \mathrm{mg}$. 2 veces al día por 3 días (20). Con esta droga se han efectuado tratamientos en masa que han producido buenos resultados, aunque la posible migración de Ascaris y la posible teratogenicidad son inconvenientes para su uso generalizado.

\section{Tiabendazol}

Este es uno de los benzimidazoles más antiguos, con rápida y potente absorción en el intestino, lo que le permite actuar contra los nemátodos de los tejidos. Es la droga de elección para estrogiloidiasis a la dosis de 25 $\mathrm{mg} / \mathrm{kg} /$ día, subdividida en 3 tomas con las comidas, durante 3 días. En algunos casos de estrongilodiasis masiva o cuando este parásito se ha diseminado por baja de las defensas orgánicas, bien sea debido a enfermedad o al uso de inmunosupresores, la dosis puede aumentarse hasta $50 \mathrm{mg} /$ $\mathrm{kg} /$ día y debe prolongarse por 5 días, repitiendo el tratamiento si es necesario (21). También es la droga de preferencia en el síndrome de migración larvaria cutánea en el cual se usa por vía oral a la dosis de 25 $\mathrm{mg} / \mathrm{kg}$ /día por 5 días y en forma tópica, utilizando la suspensión pediátrica, aplicando varias veces al día en los puntos más nuevos de los túneles, donde se encuentra la larva activa (22). Son frecuentes las manifestaciones de intolerancia, principalmente mareos, los que se producen por acción de la droga en el SNC y no por producción de hipoglicemia como se pensó antes. Otros síntomas son náuseas, vómitos, dolor abdominal, diarrea, cefalea, somnolencia y raramente eritema multiforme y síndrome de Stevens-Johnson.

\section{Niclosamida}

Esta droga actúa contra las tenias intestinales por contacto directo, en las cuales produce efectos metabólicos que las hacen desprender para ser luego eliminadas por el peristaltismo intestinal. Tiene mínima absorción en el intestino por lo cual es bien tolerada y no presenta fenómenos tóxicos. La dosis usual para T. saginta y T. solium es de $2 \mathrm{~g}$. en ayunas, previa comida líquida el día anterior. Las tabletas deben ser bien masticadas y pasadas con poca agua. Para Hymenolepis nana es necesario administrar la dosis mencionada durante 5 días y repetir este tratamiento a las 3 semanas con el fin de atacar a las nuevas tenias que evolucionaban en la mucosa intestinal (23).

\section{Praziquantel}

Este es un antihelmíntico nuevo, derivado pirazín-isoquinolínico, que se absorve rápidamente en el intestino, alcanza sus niveles mayores a las dos horas de administrado, se metaboliza en el hígado y se elimina completamente a las 24 horas, parcialmente a través de la mucosa gastrointestinal y principalmente por la orina. No se conoce completamente el mecanismo íntimo de acción, pero se sabe que actúa sobre el metabolismo de los carbohidratos en los helmintos. Los estudios experimentales han 
demostrado buena tolerancia y baja toxicidad, así como ausencia de efectos teratogénicos o mutagénicos $(24,25,26)$.

La actividad antihelmíntica es muy potente contra los plantelmintos. En la actualidad parece ser la droga más efectiva en la esquistosomiasis $(27,28)$. Entre nosotros su principal utilidad es en el tratamiento de la teniasis. Para T. saginata y T. solium hemos tenido curación en el $100 \%$ de 60 casos tratados con dosis única de 5 a $10 \mathrm{mg} / \mathrm{kg}$. En 30 casos de hymenolepiasis la curación fue de $80 \%$ con dosis única de 15 a $25 \mathrm{mg} / \mathrm{kg} /$. No se presentaron efectos secundarios y la droga no requirió dieta especial $(29,30)$. Este nuevo medicamento ha sido usado ampliamente como cestocida en animales, en los cuales es útil en tratamientos en masa. Debido a la buena tolerancia y a la eficacia de la dosis única, será posiblemente útil en tratamientos en masa contra las parasitosis humanas para las cuales ha demostrado eficacia.

Aunque los resultados son aún preliminares y el número de casos tratados no es muy grande, el praziquantel es prometedor en el tratamiento de la cisticercosis $(31,32)$. Los resultados previos en animales fueron positivos y la experiencia en humanos siempre asociado a corticoides, para combatir las posibles reacciones alérgicas e inflamatorias en el SNC, hacen pensar que esta sea la primera droga con efecto favorable contra los cisticercos. Nuestra experiencia se basa en el tratamiento de 15 casos, 2 cutáneos y 13 de neurocisticercosis, con buenos resultados (33).

\section{Levamisol}

Este antihelmíntico y su isómero tetramisol, han sido usados ampliamente en el tratamiento de infecciones por nemátodos en animales. Pertenecen al grupo de los benzimidazoles, absorbibles en el intestino, con acción sobre el sistema nervioso de los parásitos, en los que produce parálisis. La mayor utilidad del levamisol ha sido como ascaricida, para lo cual se ha utilizado en dosis única (34). Esta gran actividad lo ha hecho útil para tratamientos en masa de esta parasitosis. En la actualidad las investiga- ciones con esta droga se han orientado a su actividad inmunoestimulante, lo que ha conducido a estudios clínicos en casos de enfermedades por inmunodeficiencia y en ciertos tipos de cáncer (35), su uso prolongado ha causado en pocos casos un cuadro de agranulocitosis.

\section{Piperazina}

Este antihelmíntico puede considerarse el más antiguo de los recomendados en esta publicación. Su uso ha perdurado debido a su efectividad contra 2 parásitos frecuentes, Ascaris y Oxiuros, a su bajo precio y a la buena tolerancia (36). Contra estos helmintos actúa bloqueando las uniones mioneurales, desencadenando en éllos una parálisis flácida, por lo cual se eliminan vivos al ser arrastrados por el peristaltismo intestinal. La dosis recomendada es de $50 \mathrm{mg} / \mathrm{kg} /$ día, con un máximo de $3.5 \mathrm{gm}$. al día, durante 3 a 5 días para ascariasis y 7 días para oxiuriasis. Esta droga se absorbe activamente y se elimina por el riñón. En casos de insuficiencia renal, o cuando accidentalmente se ha ingerido una dosis muy alta, se produce un cuadro neurológico alarmante, que afortunadamente es transitorio y no deja secuelas. Los síntomas consisten en incoordinación muscular, ataxia, vértigo, debilidad muscular, contracciones mioclónicas, confusión mental y dificultad para hablar. En pacientes con predisposición puede desencadenar convulsiones epilépticas. Está contraindicado en insuficiencia renal y hepática y en pacientes epilépticos.

\section{BIBLIOGRAFIA}

\footnotetext{
1. Botero D. Clinical trial methodology in intestinal parasitic diseases. Clin. Pharmacol. Ther. 1976; 19:630.

2. Botero D. Chemotherapy of human intestinal parasitic diseases. Ann. Rev. Pharmacol. Toxicol. 1978; 18: 1 .

3. Botero D. Posibilidades de control de las geohelmintiasis mediante tratamientos en masa. Bol. Chil. Parasit. 1979; $34: 39$.

4. Botero D. Double blind study with a new nitroimidazole derivative, RO 7-0207, versus metronidazole in sympt matic intestinal amebiasis. Am. J. Trop. Med. Hyg. $1974 ; 23: 1000$.
} 
5. Asociacion Colombiana de Facultades de Medicina. Es peligroso el Flagyl? Carta Médica. 1975; 17: 26 (No. 429). Traducción de The med. Letter. 1975; 17: 21 .

6. Botero D, Bravo C. y Pérez A. Metronidazol en el trata miento de colitis amibiana disentérica y no disentérica y Giardiasis. Ant. Medica. 1971; 21: 801 .

7. Orozco H, Franco M S y Soto H. Estudio del tinidazol en el tratamiento de la rectocolitis amibiana. Tribuna Méd. 1975: Vol. 51. No. 7 (Edición 559).

8. Spillmann R, Ayala SC, De Sánchez C. E. Double-blind test of metronidazole and tinidazole in the treatment of asymptomatic Entamoeba histolytica an Entamoeba hartmanni carriers. Am J. Trop. Med. Hyg. 1976. $25: 549.51$.

9. Botero D. y Montoya M N. Giardiasis en niños. Estudio comparativo de la eficacia y tolerancia entre dos derivados imidazolicos. Tribuna Med. 1979; 60: 43.44(Edición No, 707).

10. Schwartz D E. and Jeunet F. Pharmacokinetic and metabolic studies with ornidazole in man. Comparisson with metranidazole. Chemotherapy (Basel). 1976; 22: 19-29.

11. Botero D. Effectiveness of nitromidazine in treatment of Balantidium coli infections. Trans. R. Soc. Trop. Med. Hyg. 1973; 67: 145

12. Bisseru B, Woodruff AW, Roux G, Dihydroemetine resinate in the treatment of intestinal amoebiasis. Trans R. Soc. Med. Hyg. 1965; 59: 550 .

13. Zuluaga $H$, Botero D, Vélez $H$ y Castaño A. Estudios terapéuticos y químioprofilácticos con la droga antiamibiana Win-13.146. Antioquia Med. 1971; 21:559.

14. Botero D, Rojas W, Hoyos D y Sánchez MH. Estudio Epidemiológico, terapéutico y quimioprofiláctico de amibiasis intestinal en el Muncipio de Apartadó. Ant. Médica. $1971 ; 21: 217$

15. Botero D, Cano M, Pérez MA y Hurtado MI, Furazolidona en giardiasis intestinal. Rev. Inv. Salud Püblica (México). $1973 ; 33: 127$.

16. Botero D, Helmiantiasis Intestinales. Tratamiento en masa con pamoato de Pirantel. Estudio en una población rural de Colombia, Municipio de Heliconia. Tribuna Médica. 1974: 50: A 21

17. García EG, Treatment of Trichuriasis with oxantel. Am J. Trop. Med. Hyg. 1976; 25: 914.

18. Banzon रे $C$, Singson $C$, and Cross $J H$. Mebendazol treatment for intestinal nematodes in a Phiplippine Barrio. J. Philip. Med. Assoc. 1976; 52:7

19. Botero D, Pérez CA. Tratamiento de helmintiasis intesti nales con mebendazole. Trib. Méd. Colombia 1976; 54: 30.

20. Peña.Chavarria $A, V i l l a r e j o s ~ V M, Z$ eledon $R, M e b e n d a z o l e$ in the treatment of taeniasis solium and taeniasis saginata. Am. J. Trop. Med. Hyg. 1977; 26: 118.
21. Scowden, E.B. et al. Overwhelming strongyloidiasis. An unappreciated opportunisitc infection. Medicine. 1978; 57: 527 .

22. Stone $O$, and Mullins JF. Thiabendazole Therapy for creeping eruption. Arch. of Dermat. 1964; 89: 557.

23. Amato-neto $V$ Campos R. Tratamiento por un derivado de Salicilamida, de infestacoes causadas por Taenia saginata e Taenia solium?. Rev. Inst. Med. Trop. Sao Paulo. 1964; 6: 297

24. Leopold G. et: al. Clinical pharmocology in normal volunteers of praziquiantel a new drug against Schistosomes and Cestodes. Europ. J. clin. Pharmacol. $1978 ; 14: 281$.

25. Buhring $K U$, et al. Metabolism of praziquantel in man. Europ. J. Drug Metabol. And Pharmacokinetics. 1978. No. 3: 179 .

26. Bartsch H, et al. Abscense of mutagenicity of praziquian tel, a new effective, anti-schistosomal drug, in bacteria, reast, insects and mammalian cells. Mutation Research. $1978 ; 58: 133$.

27. Katz N, Rocha RS Chaves A. Preliminary trials with praziquantel in human infections due to Schistosoma mansoni. Bull. WHO. 1979; $57: 781$.

28. Davis A, Biles JE Uirich AM. Initial experiences with praziquantel in the treatment of human infections due to Schistosoma haematobium. Bull. WHO; 1979; 57: 773.

29. Botero D y Ocampo NE. Tratamiento de teniasis y de hymenolepiasis con praziquantel. Federación Latinoame. ricana de Parasitólogos. Resúmenes de Trabajos, V Congreso Latinoamericano de Parasitología. Bs. Aires. Argentina. 1979.

30. Groll E. Panoramageneral del tratamiento de las infeccio nes hum anas por cestodes con praziquantel (Embay 8440 ). Bol. Chile. Parasit. 1977; 32: 27.

31. Robles C y Chavarria M. Un caso de cisticercosis cerebral curado médicamente. Gaceta Med. de México. 1980; 116:65

32. Spina-Franca A y Nobrega J.P.S. Neurocisticercose e praziquantel. Revta. Paul. Med. $1980 ; 95: 34-36$

33. Botero D y Castaño S. Tratamiento de cisticercosis huma na con praziquantel. Trabajo presentado en el $X$ Congreso Internacional de Medicina Tropical y Malaria, Manila, Filipinas. 1980 y en el Congreso Nacional de Ciencias Neurológicas, Cali, Colombia, 1980.

34. Moens $M$. et al. Levamisole in ascariasis. A multicenter controlled evaluation. Am. J, Trop. Med. Hyg. 1978; 27: 897 .

35. Renoux G, Renoux $M$, Teller MN, McMahon S, Guillaum in JM. Potentiation of $T$-cell mediated immunity by levamisole. Clin. Exp. Immunol 1976; 25: 288-96.

36. Davis A. Drug. Treatment of Intestinal Helminthiasis. Geneva: WHO. $1973 ; 125$ pp. 